UDC 551.578.46

LBC 26.237

\title{
INFLUENCE OF FIELD-PROTECTIVE FOREST BELTS OF OPENWORK CONSTRUCTION ON THE CHARACTER OF SNOW DISTRIBUTION
}

\author{
Yustina N. Potashkina \\ Federal Scientific Centre of Agroecology, Complex Melioration and Protective Afforestation \\ of the Russian Academy of Sciences, Volgograd, Russian Federation
}

Elena A. Ivantsova

Volgograd State University, Volgograd, Russian Federation

\begin{abstract}
Snow in agricultural landscapes is a reserve of moisture, as well as protection of soils from deep freezing and protection of wintering plants from destructive effects of low temperatures. In the zone of insufficient moisture to which the study area belongs, the snow cover is one of the main sources of water resources, as the moisture reserves in the soil, necessary for growth and development of agricultural crops, are formed to a greater extent by meltwater infiltration. Forest belts have a direct impact on snow accumulation and character of snow deposition. The purpose of this work is to study the effect of openwork forest shelter belts on snow accumulation and snow distribution in agricultural landscapes in Ilovlinsky District of Volgograd Oblast. The snow cover was studied in the top-down direction along the slope (perpendicular to the forest belt (FB)) by laying snow measuring profiles, along which the height of the snow cover was measured with a snow measuring rod M-46 in triplicate (in the field part every $4 \mathrm{~m}$, in the forest belt and plume zones every meter). According to the results of the studies, the main zones of snow accumulation were identified: the first zone (I) - the forest belt, the second (II) - the zone of snow plume formation, the third (III) - the zone of FB influence (up to $30 \mathrm{H}$, where $\mathrm{H}$ is the plantation height), the fourth (IV) - the entire field part of the agricultural landscape. It was found that the maximum values of snow cover were recorded in the forest belt, as well as in the plume zone $(1-2 \mathrm{H})$. The average snow height in the field part at the level is $7 \mathrm{~cm}$, which is $14 \mathrm{~cm}$ lower than the snow height in the FB influence zone $(1-30 \mathrm{H})$. In some parts of the field, $\vec{\delta}$ the snow cover height is reduced to $5 \mathrm{~cm}$. The results obtained can be used to solve various agronomic as well as

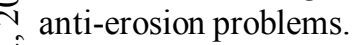

Key words: agrolandscape, snow distribution, forest belt, snow height, agroforestry.

Citation. Potashkina Yu.N., Ivantsova E.A. Influence of Field-Protective Forest Belts of Openwork Construction on the Character of Snow Distribution. Prirodnye sistemy i resursy [Natural Systems and Resources], 2021, vol. 11, no. 4, pp. 31-36. DOI: https://doi.org/10.15688/nsr.jvolsu.2021.4.3 
УДК 551.578 .46

ББК 26.237

\title{
ВЛИЯНИЕ ПОЛЕЗАЩИТНЫХ ЛЕСНЫХ ПОЛОС АЖУРНОЙ КОНСТРУКЦИИ НА ХАРАКТЕР СНЕГОРАСПРЕДЕЛЕНИЯ
}

\author{
Юстина Николаевна Поташкина \\ Федеральный научный центр агроэкологии, комплексных мелиораций и защитного лесоразведения РАН, \\ г. Волгоград, Российская Федерация
}

Елена Анатольевна Иванцова

Волгоградский государственный университет, г. Волгоград, Российская Федерация

\begin{abstract}
Аннотация. Снег в агроландшафтах - это резерв влаги, а также защита почв от глубокого промерзания, а зимующих растений - от губительного действия низких температур. В зоне недостаточного увлажнения, к которому относится район исследования, снежный покров относится к основным источникам водных ресурсов, так как запасы влаги в почве, необходимые для роста и развития сельскохозяйственных культур, в большей степени формируются за счет инфильтрации талых вод. Лесополосы оказывают прямое воздействие на снегонакопление и характер снегоотложения. Целью работы является изучение влияния полезащитных лесополос ажурной конструкции (ПЗЛП) на снегоотложение и характер снегораспределения в агроландшафтах в Иловлинского района Волгоградской области. Изучение снежного покрова осуществлялось в направлении сверху вниз по склону (перпендикулярно к лесной полосе (ЛП)) путем прокладки снегомерных профилей, на протяжении которых измерялась высота снежного покрова снегомерной рейкой М-46 в трехкратной повторности (в полевой части через каждые 4 м, в лесной полосе и шлейфовых зонах через каждый метр). По результатам исследований были выделены основные зоны аккумуляции снега: первая зона (I) лесная полоса, вторая (II) - зона образования снежных шлейфов, третья (III) - зона влияния ЛП (до $30 \mathrm{H}$, где H - высота насаждения), четвертая (IV) - вся полевая часть агроландшафта. Установлено, что максимальные значения снежного покрова зафиксированы в лесной полосе, а также в шлейфовой зоне (1-2Н). Средняя высота снега в полевой части на уровне составляет 7 см, что на 14 см ниже чем в высота снега в зоне влияния ЛП (1-30Н). На некоторых участках поля высота снежного покрова снижается до 5 см. Полученные результаты могут быть использованы для решения различных агрономических, а также противоэрозионных задач.

Ключевые слова: агроландшафт, снегораспределение, лесная полоса, высота снега, агролесомелиорация.
\end{abstract}

Цитирование. Поташкина Ю. Н., Иванцова Е. А. Влияние полезащитных лесных полос ажурной конструкции на характер снегораспределения // Природные системы и ресурсы. - 2021 . - Т. 11, № 4. - С. 31-36. DOI: https://doi.org/10.15688/nsr.jvolsu.2021.4.3

\section{Ведение}

Снег для большинства сельскохозяйственных районов - это, прежде всего, резерв влаги, а также защита почв от глубокого промерзания, а зимующих растений - от губительного действия низких температур [1]. Снежный покров существенно воздействует на различные культуры, в большей степени на озимые. Так, снежный покров является своеобразным барьером, между почвой и атмосферой препятствуя при этом прогреванию или таянию почвы, обладая малой теплопроводностью. Теплопроводность снега в отличие от поверхности почвы примерно в 10 раз меньше почвы. Из-за малой теплопроводности снеж- ный покров защищает культуры от влияния низких температур, резких колебаний температур, защищает почву от глубокого промерзания [7]. На промерзание и температуру почвы также оказывают влияние не только высота снежного покрова, но и плотность. Уплотненный снежный покров способствует более быстрому охлаждению почвы. Известно, что территории со сплошным снежным покровом в менышей степени подвержены солнечной инсоляции.

В зоне недостаточного увлажнения, к которому относится район исследования (Волгоградская область, Иловлинский район), снежный покров относится к основным источникам водных ресурсов, так как запасы влаги в почве, необходимые для роста и развития 
сельскохозяйственных культур, в большей степени формируются за счет инфильтрации талых вод [6; 7]. Лесополосы оказывают прямое воздействие на снегонакопление и характер снегоотложения [2; 3]. Однако, это влияние напрямую зависит от ряда факторов, а именно: от ветрового режима, способа размещения лесных насаждений, их конструкция и параметры (количество рядов, ширина и др.), а также расстояния между ними $[4 ; 5 ; 8]$.

Объектом исследования являлась четырехрядная полезащитная лесная полоса ажурной конструкции, расположенная на сельскохозяйственных землях в Иловлинском районе Волгоградской области. Возраст насаждений - около 40 лет, видовой состав состоит преимущественно из вяза мелколистного (Ulmus parvifolia J.), а также смородины золотистой (Ribes aureum Р.) по краям полосы. Почвенный покров агроландшафтов Иловлинского района представлен в основном освоенными типичными каштановыми почвами в комплексе с солонцами каштановыми, а также лугово-каштановыми в балках и микропонижениях.

Цель работы - изучение влияния полезащитных лесополос ажурной конструкции (ПЗЛП) на снегоотложение и характер снегораспределения в агроландшафтах Иловлинского района Волгоградской области.

Материал и методы. Изучение снежного покрова осуществлялось в направлении сверху вниз по склону (перпендикулярно к лесной полосе (ЛП)) путем прокладки снегомерных профилей, на протяжении которых измерялась высота снежного покрова снегомерной рейкой M-46 в трехкратной повторности (в полевой части через каждые 4 м, в лесной полосе и шлейфовых зонах через каждый метр). Все опытные данные в дальнейшем обрабатывались программном обеспечении XLstat 2016. В качестве статистических показателей были выбраны следующие: минимальные и максимальные значения, нижний квартиль и верхний квартили, медиана, среднее арифметическое, среднеквадратическое отклонение, коэффициент вариации, а также стандартная ошибка средней.

\section{Результаты и обсуждение}

На рисунке 1 представлен профиль снегораспределения под влиянием лесной полосы. Для выявления роли лесной полосы на характер снегораспределения и мощность снежного покрова нами выделены четыре характерные зоны аккумуляции снега. Первая зона (I) - лесная полоса, вторая (II) - зона образования снежных шлейфов, третья (III) зона влияния ЛП (до $30 \mathrm{H}$, где Н - высота насаждения), четвертая зона (IV) - вся полевая часть агроландшафта.

Первая зона (I) - лесная полоса. Наибольшая мощность снега во всем агроландшафте наблюдалась в первой зоне - зоне лесных полос. Максимальные значения высоты снега зафиксированы в 4 ряду ЛП - до 36 см. В целом распределение снега в лесной полосе носит аккумулятивный характер по краям полосы в кустарниках. Высота снежного покрова во втором, третьем ряду, а также междурядьях колеблется от 6 до 23 см. Средняя высота снега в насаждении составляла около 21 см (см. таблицу).

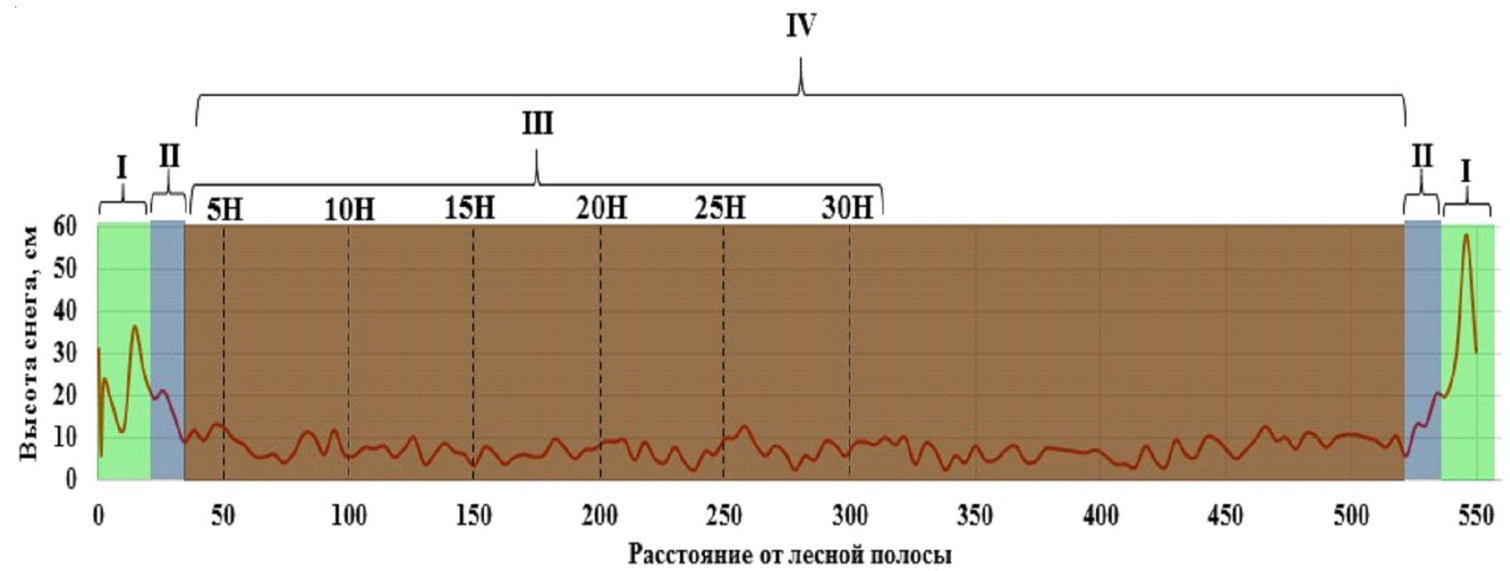

Рис. 1. Профиль снегораспределения под влиянием лесной полосы 


\section{РЕСУ РСОВЕДЕНИЕ}

Вторая зона (II) - зона снежных шлейфов. Далее от лесной полосы нами была выделена шлейфовая зона. Длина этой зоны составляет 12 м. Средняя высота снега в ней около 20 см, максимальная высота -26 см, минимальная - 15 см. Образование снежных шлейфов обусловлено действием ветра. Поскольку лесная полоса имеет ажурную конструкцию скорость ветра в агроландшафте носит экспоненциальный характер, то есть ветровой поток приближаясь к лесной полосе снижает свою скорость и огибает ее сверху. После шлейфовой зоны выделяется зона полевой части (III зона).

Третья (III) - зона влияния ЛП (до 30Н). Общая длина этой зоны составляет 488 м. Для выделения роли ЛП на снегораспределение и снегонакопление на поле нами отдельно было изучено накопление и распределение снега в зоне влияния ЛП и во всем агроландшафте в целом. Установлено, что в зоне влияния ЛП максимальная высота снега фиксируется на $1-2 \mathrm{H}$ и составляет 26 см. Средняя высота от ЛП до $30 \mathrm{H}$ - на уровне $21 \mathrm{~cm}$. На некоторых участках поля высота снежного покрова снижалась до 5 см (рис. 2).
Четвертая зона (IV) - вся полевая часть агроландшафта. В целом высота снежного покрова во всем агроландшафте (от одной лесной полосы до другой) составляло 7 см (max - 13 см, min - 2 см). На поле наблюдались участки с полным отсутствием снега. Распределение снега во всем агроландшафте из-за незначительной высоты снега было относительно равномерным, лишь на некоторых участках мощность снега увеличивается до 12 см.

\section{Заключение}

Таким образом, проанализировав данные о влиянии ПЗЛП на характер распределения и накопления снега в агроландшафтах Иловлинского района Волгоградской области можно сделать вывод, что при установлении роли ЛП необходимо выделение следующих зон аккумуляции снега: первая зона (I) - лесная полоса, вторая (II) - зона образования снежных шлейфов, третья (III) - зона влияния ЛП (до $30 \mathrm{H}$, где Н - высота насаждения), четвертая (IV) - вся полевая часть агроландшафта. Установлено, что максимальные значения

\section{Общее варьирование мощностей снежного покрова по элементам агроландшафта}

\begin{tabular}{|l|c|c|c|c|c|c|c|c|c|c|}
\hline \multicolumn{1}{|c|}{ Высота снега, см } & $\mathrm{n}$ & $\min$ & $\mathrm{Q} 1$ & $\operatorname{med}$ & $\mathrm{Q} 3$ & $\max$ & $\mathrm{M}$ & $\mathrm{s}$ & $\mathrm{V}, \%$ & $\mathrm{x} \pm \mathrm{m}$ \\
\hline ЛП & 14 & 6 & 14 & 21 & 29 & 36 & 21 & 10,424 & 0,494 & 4,66 \\
\hline Зона шлейфа & 15 & 15 & 18 & 20 & 22 & 26 & 20 & 3,703 & 0,182 & 2,14 \\
\hline $1-30 \mathrm{H}$ & 219 & 2,3 & 5,6 & 7,3 & 9 & 25,6 & 7,9 & 3,902 & 0,491 & 0,28 \\
\hline Вся полевая часть & 369 & 2 & 6 & 7 & 9 & 13 & 7 & 2,450 & 0,337 & 0,25 \\
\hline
\end{tabular}

Примечание. Статистические показатели: $\mathrm{n}$ - объем выборки; $\min$ - минимум; Q1 - нижний квартиль; med - медиана; Q3 - верхний квартиль; max - максимум; M - среднее арифметическое; s - среднеквадратическое отклонение; $\mathrm{V}$ - коэффициент вариации; $\mathrm{x} \pm \mathrm{m}$ - стандартная ошибка средней.

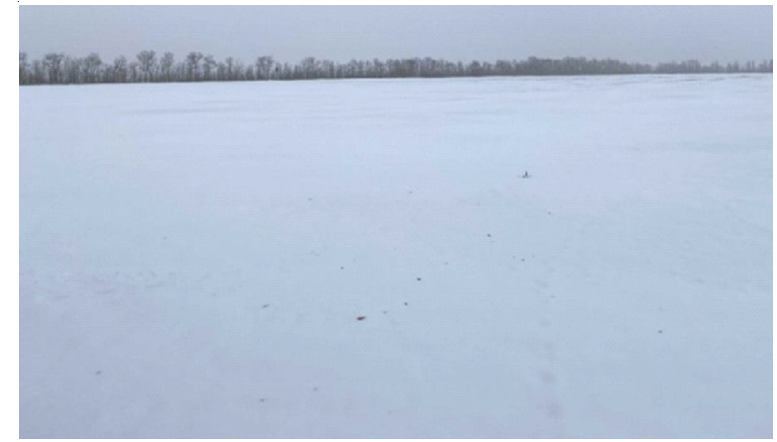

A)

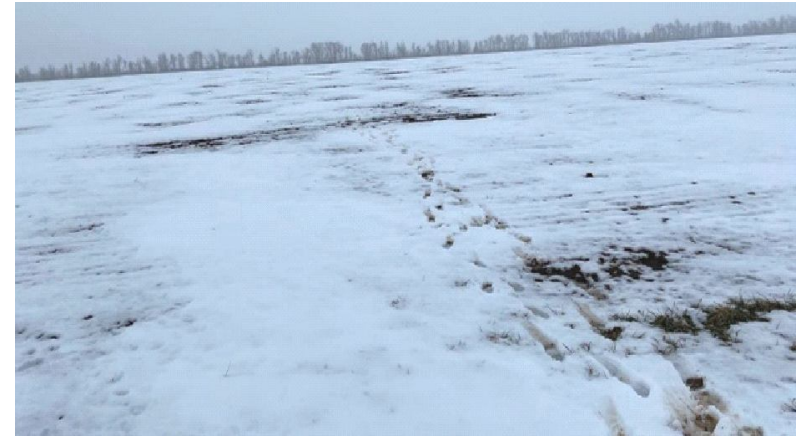

Б)

Рис. 2. Общий вид снегораспределения в агроландшафте (А) и места полного или частичного отсутствия снежного покрова (Б) 
снежного покрова зафиксированы в лесной полосе, а также в шлейфовой зоне (1-2Н). Среднее значение высоты снега в полевой части составляло 7 см, что на 14 см ниже, чем значение высоты снега в зоне влияния ЛП (1-30Н). На некоторых участках поля высота снежного покрова снижалась до 5 см, или снежный покров отсутствовал полностью. Полученные результаты исследований могут быть использованы для решения различных агрономических, а также противоэрозионных задач в лесоаграрных ландшафтах Волгоградской области.

\section{СПИСОК ЛИТЕРАТУРЫ}

1. Верин, А. Ю. Экологическое состояние почвы в системе «почва - лесные насаждения» / А. Ю. Верин, И. Ф. Медведев // Известия Саратовского университета. Новая серия. Серия: Химия. Биология. Экология. - 2020. - Т. 20, № 2. C. 226-231. DOI: https://doi.org/10.18500/1816-97752020-20-2-226-231.

2. Иванцова, Е. А. Агроэкологическое значение защитных лесных насаждений в Нижнем Поволжье / Е. А. Иванцова // Вестник Волгоградского государственного университета. Серия 11, Естественные науки. - 2014. - № 4 (10). - С. 40-47. - DOI: http://dx.doi.org/10.15688/jvolsu11.2014.4.5.

3. Иванцова, Е. А. Устойчивое развитие агроэкосистем / Е. А. Иванцова, А. А. Матвеева, Ю. С. Половинкина // Антропогенная трансформация геопространства: история и современность : материалы Всерос. науч.-практ. конф. - Волгоград : Изд-во ВолГУ, 2014. - С. 27-30.

4. Узолин, А. И. Эффективность защитных лесных полос в формировании и перераспределении снежного покрова на водосборах / А. И. Узолин, А. В. Кулик // Известия Нижневолжского агроуниверситетского комплекса: Наука и высшее профессиональное образование. - 2018. - Т. 2, № 50.C. $100-106$.

5. Ivonin, V. M. Flow-Regulating Capacity of Forest Belts in Connection with Their Taxation Characteristics / V. M. Ivonin // Scientific Journal of Russian Scientific Research Institute of Land Improvement Problems. - 2021. - Vol. 11, № 1. - P. 8196. - DOI: https://doi.org/10.31774/2222-1816-202111-1-81-96.

6. Effects of Shelterbelts on Snow Distribution and Sublimation / J. Kort [et al.] // Agroforestri Systems. - 2011. - Vol. 86, № 3. - P. 335-344. - DOI: https://doi.org/10.1007/s10457-011-9466-4.
7. Sidorenko, S. V. Features of Snow and Moisture Distribution Under the Influence of Shelter Belts of Dense Construction / S. V. Sidorenko, Y. M. Bila // Forestry and Forest Melioration. - 2018.№ 131. - P. 104-112.

8. Vavin V. S. Snow-Regulating Role of Forest Belts Depending on the Field Area / V. S. Vavin, A. V. Popov, V. Yu. Syromyatnikov // IOP Conference Series Earth and Environmental Science. - 2019. Vol. 392. -DOI: https://doi.org/10.1088/1755-1315/392/ $1 / 011001$.

\section{REFERENCES}

1. Verin A.Yu., Medvedev I.F. Ekologicheskoe sostoyanie pochvy v sisteme "pochva - lesnye nasazhdeniya» [Ecological State of Soil in the System "Soil - Forest Plants"]. Izvestiya Saratovskogo universiteta. Novaya seriya. Seriya: Himiya. Biologiya. Ekologiya [Izvestiya of Saratov University. New Series. Series: Chemistry. Biology. Ecology], 2020, vol. 20, no. 2, pp. 226-231. DOI: https://doi.org/ 10.18500/1816-9775-2020-20-2-226-231.

2. Ivantsova E.A. Agrojekologicheskoe znachenie zasgitnyh lesnyh nasazhdenij v Nizgnem Povolzhje [Agroecological Importance of the Protective Forest Plantings in the Lower Volga Region]. Vestnik Volgogradskogo gosudarstvennogo universiteta. Seria 11, Estestvennye nauki, 2014, no. 4 (10), pp. 40-47. DOI: http://dx.doi.org/10.15688/ jvolsu11.2014.4.5.

3. Ivantsova E.A., Matveeva A.A., Polovinkina Yu.S. Ustoichivoe razvitie agroekosistem [Sustainable Development of the Agroecosystem]. Antropogennaya transformaciya geoprostranstva: istoriya i sovremennost: materialy Vserossuisknoi nauchno-prakticheskoi konferencii [Anthropogenic Transformation of Geospatial: History and Modernity. Proceedings of the All-Russian Scientific and Practical Conference]. Volgograd, Izd-vo VolGU, 2014, pp. 27-30.

4. Uzolin A.I., Kulik A.V. Effektivnost' zashchitnyh lesnyh polos $\mathrm{v}$ formirovanii i pereraspredelenii snezhnogo pokrova na vodosborah [Efficiency of Protective Forest Belts in Formation and Redistribution of Snow Cover at Watersheds]. Izvestiya Nizhnevolzhskogo agrouniversitetskogo kompleksa: Nauka i vysshee professional'noe obrazovanie, 2018, vol. 2, no. 50, pp. 100-106.

5. Ivonin V.M. Flow-Regulating Capacity of Forest Belts in Connection with Their Taxation Characteristics. Scientific Journal of Russian Scientific Research Institute of Land Improvement Problems, 2021, vol. 11, no. 1, pp. 81-96. DOI: https:// doi.org/10.31774/2222-1816-2021-11-1-81-96. 


\section{РЕСУРСОВЕДЕНИЕ}

6. Kort J., Bank G., Pomeroy J., Fang X. Effects of Shelterbelts on Snow Distribution and Sublimation. Agroforestri Systems, 2011, vol. 86, no. 3, pp. 335-344. DOI: https://doi.org/10.1007/ s10457-011-9466-4.

7. Sidorenko S.V., Bila Y.M. Features of Snow and Moisture Distribution Under the Influence of
Shelter Belts of Dense Construction. Forestry and Forest Melioration, 2018, no. 131, pp. 104-112.

8. Vavin V.S., Popov A.V., Syromyatnikov V.Yu Snow-Regulating Role of Forest Belts Depending on the Field Area. IOP Conference Series Earth and Environmental Science, 2019, vol. 392. DOI: https:// doi.org/10.1088/1755-1315/392/1/011001.

\section{Information About the Authors}

Yustina N. Potashkina, Junior Researcher, Laboratory of Agricultural Technologies and Farming Systems in the Agroforest Landscapes, Federal Scientific Centre of Agroecology, Complex Melioration and Protective Afforestation of the Russian Academy of Sciences, Prosp. Universitetsky, 97, 400062 Volgograd, Russian Federation, potashkina-y@vfanc.ru

Elena A. Ivantsova, Doctor of Sciences (Agriculture), Professor, Director of the Institute of Natural Sciences, Volgograd State University, Prosp. Universitetsky, 100, 400062 Volgograd, Russian Federation, ivantsova.volgu@mail.ru

\section{Информация об авторах}

Юстина Николаевна Поташкина, младший научный сотрудник лаборатории агротехнологий и систем земледелия в агролесоландшафтах, Федеральный научный центр агроэкологии, комплексных мелиораций и защитного лесоразведения РАН, просп. Университетский, 97, 400062 г. Волгоград, Российская Федерация, potashkina-y@vfanc.ru

Елена Анатольевна Иванцова, доктор сельскохозяйственных наук, профессор, директор института естественных наук, Волгоградский государственный университет, просп. Университетский, 100, 400062 г. Волгоград, Российская Федерация, ivantsova.volgu@mail.ru 